DOI: https://doi.org/10.47405/mjssh.v6i9.1108

\begin{tabular}{|c|c|}
\hline 4.581 & Malaysian Journal of Social Sciences and Humanities (MJSSH) \\
\hline $\begin{array}{l}\text { Malaysian Journal of } \\
\text { Social cciences and }\end{array}$ & Volume 6, Issue 10, October 2021 \\
\hline (MJ-SSH) & e-ISSN : 2504-8562 \\
\hline & $\begin{array}{l}\text { Journal home page: } \\
\text { www.msocialsciences.com }\end{array}$ \\
\hline
\end{tabular}

\title{
The Instructional Design of Chinese Characters' Stroke Order Motion Graphics Based on Cognitive Load Theory
}

\author{
Wenjun Cao', Julina Ismail@Kamal' ${ }^{1}$, Chu Hiang Goh ${ }^{2}$ \\ 1Department of New Media Design and Technology, School of the Arts, Universiti Sains Malaysia, Malaysia \\ 2Department of Graphic Communication Design, School of the Arts, Universiti Sains Malaysia, Malaysia \\ Correspondence: Wenjun Cao (xingyu602@outlook.com)
}

\begin{abstract}
This research aims to develop stroke order motion graphics for Chinese characters to solve the problem of memorising Chinese characters' stroke order in the learning process. This research adopted cognitive load theory and the ADDIE model as an instructional design process guide. Herbart's fourstage teaching method is used as a guide for the motion graphics presentation module. Based on the characteristics of Malaysian students who learn Chinese as their second language, motion graphics for Chinese characters' stroke order learning were developed. The expert evaluation was conducted to identify problems, and modifications were done to improve the created prototype. A total of six Chinese characters' stroke order motion graphics have been successfully developed. The result shows that cognitive load theory provides an effective solution for developing Chinese characters' stroke order motion graphics. The ADDIE model also offered a significant direction for the instructional design process. In addition, to be more effective in Chinese character stroke order teaching, interface design must consider the relevant teaching effects of cognitive load theory. However, making the prototype in advance can avoid large-scale modifications in the later process. The successful development of the Chinese characters' stroke order motion graphics allows teaching Chinese character stroke order in Malaysia to be carried out more effectively.
\end{abstract}

Keywords: motion graphic, cognitive load theory, ADDIE model

\section{Introduction}

Learning the Chinese language has become a trend globally(Ding \& Saunders, 2006). However, the Chinese characters are difficult to learn, especially for those who learn Chinese as a second language (Packard, 1990). Memorising the stroke order of Chinese characters can be a challenging process (Hsiung et al., 2017). It causes some learners to focus on learning the spoken language instead of learning the Chinese characters or even giving up. Rote memorisation is a way of memorising the stroke order of Chinese characters commonly used by students who learn Chinese as a second language (Taft \& Chung, 1999). Traditionally, the teacher writes the Chinese characters stroke order once on the blackboard, and the students follow it. However, students have problems remembering the stroke order after the class. Some researchers have developed stroke order animations of Chinese characters $(\mathrm{Li}$, 2003; Zhu \& Wang, 2013) intending to solve the problem. These animations show the writing steps of Chinese characters in a dynamic form. However, it does not change the current situation of rote learning. It only serves as an alternative tool for learning when the teacher is not around. Still, it does not teach students how to memorise the stroke order of Chinese characters, which is essential in this 
context. Teaching students to efficiently memorise the stroke order of Chinese characters has become a major problem in teaching Chinese as a foreign language. It appears to be a significant gap in the research to improve Chinese characters stroke order learning.

To solve the problem of memorising the stroke order of Chinese characters, the authors developed the stroke order motion graphics of Chinese characters. As a learning tool, motion graphics can improve learners' learning performance has been proven better than traditional animation. It has the advantage of delivering complex information in a shorter time.

This paper introduced the development process of the stroke order motion graphics for Chinese characters and reported the review opinions by animation experts.

\section{Literature Review}

Animation is used as one of the functioning tools in education. The essence of educational animation is to help students understand complex learning materials, especially phenomena and abstract concepts that cannot be perceived in reality(Mason et al., 2013). Animation can be used as an auxiliary teaching tool to improve students' learning efficiency.

Australian psychologist John Sweller proposed cognitive load theory in 1988 based on working memory theory, schema theory, and limited cognitive resources theory (Sweller, 1988). It emphasises that people's working memory resources are limited; when cognitive resources exceed working memory space and are overloaded, it will lead to a phenomenon described as cognitive load. Cognitive load is an important factor that affects the effectiveness of teaching activities. The cognitive load theory aims to reduce intrinsic and extraneous cognitive load and increase the germane cognitive load (Leppink \& van den Heuvel, 2015). The cognitive load theory has produced a series of teaching effects, such as redundancy, split-attention, imagination, and isolated interacting elements. These teaching effects provide guidance for instructional design so that instructional designers can choose complementary teaching strategies according to the actual situation.

In recent years, many educational animation studies have begun to adopt cognitive load theory in its process.Marcus et al. (2013)use cognitive load theory to predict whether two animation conditions (hands and no hands) will be equally effective. They randomly assigned 36 adults to three groups of hand animation, handless animation, and static graphics. The results show that hand motion has a higher teaching efficiency than handless animation. In order to investigate the influence of the rhythm controlled by learners in educational animation on teaching efficiency, Hasler et al. (2007) presented it to primary school students through three versions of animation and narrative presentation. The results show that the animation group leads to a low cognitive load. Wong et al. (2012) explore the transient effects caused by animation-based instructions and spoken information under audio-visual conditions based on cognitive load theory. The results show that animation is better than static graphics. Although these studies show that the cognitive load theory is applied to educational animation with good results, motion graphics are manifestations of animation, the study of cognitive load theory applied to motion graphic instructional design is still rare. This article is based on the cognitive load theory to explore the teaching design of Chinese characters' stroke order motion graphic, which has important guiding significance for teaching Chinese stroke order in Malaysia.

\section{Methodology}

In this research, instructional design is defined as the use of systematic methods to solve instructional problems. This research adopted Richey \& Kleins' (2014) educational design and development research methodology to develop the research design. Cognitive load theory was used to provide theoretical guidance for the specific implementation of the development process. We further explore the influencing factors of cognitive load by analysing the three types of cognitive loads and put forward particular applications according to the relevant strategies to control the cognitive loads. 
ADDIE model was used as a guide for the instructional design of stroke order motion graphics of Chinese characters. The ADDIE model is widely used by instructional designers and training developers(Rita C Richey \& James D Klein, 2014). The model contains five stages, namely analysis, design, development, implementation, and evaluation. Modifications were made to suit the requirement of this research. The design stages are as follows:

i. Analysis: This stage mainly analyses the characteristics of learners, analyses the needs of the development of Chinese character stroke order motion graphics, and selects teaching materials and development tools.

ii. Design: Justifying instructional design strategies and how to choose present modules.

iii. Development: Determine the development process of Chinese characters' stroke order motion graphics and develop it.

iv. Implementation: Expert evaluation - to further modify and improve Chinese characters' stroke order motion graphics.

v. Evaluation: Target audience evaluation - to measure students' learning performance and cognitive load, and ask about their opinions through questionnaires.

This is ongoing research. This paper will present the design process of step 1 to step 4 , as step 5 involves further investigation and measurements of the target audience's responses. It will be presented in our future publication.

\section{Result}

\section{Analysis}

\section{Analyse the learners' characteristics and the needs of the Chinese characters stroke order motion graphics development.}

The Chinese characters strokes have no practical meaning. The traditional teaching method involves rote learning, which allows students to practice repeatedly(Tan et al., 2005). It makes the learning method of students very mechanical. For the learning of Chinese characters, it is inadequate only to remember the strokes. One needs to memorise the sequence order of the strokes of the Chinese character, which causes a higher cognitive load. The stroke order motion graphics of Chinese characters developed in this paper use the approach of understanding memory to help students in Malaysia learn the stroke order because it is a more effective way than the traditional mechanical rote practice. Through classroom observations, we found that the learners prefer animated teaching methods such as motion graphics, which is consistent with previous research results(Fatimah \& Santiana, 2017).

The participants of this research are Malaysian undergraduate students who use Chinese as a second language. In terms of cognitive development, university students are more inclined to imageries and logical thinking. In terms of memory, university students are good at both image memory and abstract memories. However, they relatively lack creative thinking. It requires that Chinese characters' stroke order motion graphics be fully prepared in advance to evoke creativity and promote creative thinking among the students.

Malaysia has a unique educational background. Malaysia is a country where Malay is the first official language, and English is the second official language. Therefore, Malaysian university students speak both languages. Since the students understand English well, Chinese characters' stroke order motion graphics use English as the narration language. 


\section{Selection of teaching materials}

The author randomly selected three students for the test. They have zero foundation in learning the Chinese language. The results show that they can't write Chinese characters with more than five strokes, which is consistent with George Miller's research results(Miller, 1956). The highest number of strokes in the single character table is eleven, so we randomly selected six Chinese characters from five to eleven, namely Sheng(生), Yang (羊), Lai (来), Shi (事), Zhong (重), and Xiang (象) in this context.

\section{Selection of design tools}

The requirements of the featured motion graphic design tools must be inclusiveness and able to mix and match with various artistic styles. The analysis of currently available mainstream software that can be used for motion graphic design and production are shown in the table below:

Table1: Design software for motion graphic design

\begin{tabular}{ccccc}
\hline $\begin{array}{c}\text { Graphic design } \\
\text { software }\end{array}$ & $\begin{array}{c}\text { Animation design } \\
\text { software }\end{array}$ & $\begin{array}{c}\text { Audio editing } \\
\text { software }\end{array}$ & $\begin{array}{c}\text { Special } \\
\text { effects } \\
\text { synthesis } \\
\text { software }\end{array}$ & $\begin{array}{c}\text { Video editing } \\
\text { software }\end{array}$ \\
$\begin{array}{c}\text { Adobe } \\
\text { Photoshop, } \\
\text { Adobe } \\
\text { Illustrator }\end{array}$ & $\begin{array}{c}\text { Autodesk Maya, } \\
\text { Autodesk 3ds Max, } \\
\text { Adobe Animate } \\
\text { (Adobe Flash), } \\
\text { Cinema 4D }\end{array}$ & Adobe Audition & $\begin{array}{c}\text { Adobe After } \\
\text { Effects, } \\
\text { Nuke, Fusion }\end{array}$ & $\begin{array}{c}\text { Edius, } \\
\text { Adobe Premiere, } \\
\text { Vegas }\end{array}$ \\
\hline
\end{tabular}

To avoid technical problems such as incompatibility between software in the postproduction process, the authors decided to use mixed Adobe's design software for the development process. Namely, Adobe Photoshop, Adobe Animate (Adobe Flash), Adobe Audition, Adobe After Effects, Adobe Premiere are used to develop the characters' stroke order motion graphics.

\section{Design}

\section{Strategies and Application of Reducing Intrinsic Cognitive Load}

The intrinsic cognitive load is determined by the complexity of the learning materials and the learner's original knowledge level(Sweller, 1994). The complexity of learning materials involves the degree of interaction between elements and is closely related to the number of elements in the learning process. Regarding the learning materials with low interaction, learners can easily understand and complete learning tasks easily due to the low level of interaction between elements. While learning materials with high interaction and involve more elements, learners have difficulty understanding, and they will devote more cognitive resources, resulting in a higher internal cognitive load(Sweller, 2010). According to the isolated-interacting element's effect, when dealing with highly interactive learning content, which involves many interactive elements, learners cannot deal with them simultaneously. These elements can be separated during instructional design. Present each element separately. Strokes are the basic unit of Chinese characters and the basis for memorising the stroke order of Chinese characters. For beginners, memorizing the strokes of Chinese characters is the first step of their learning process. Therefore, when designing teaching instruction, we can consider disassembling Chinese characters and splitting them into individual stroke, and let the learners learn it separately.

Although modern scholars believe that Chinese characters are derived from graphic forms(Zhen, 2015), the simplified form of Chinese characters has undergone significant changes throughout the years. The shapes have become abstract and unified-learners who learn Chinese as a second language have difficulty recognising even the most straightforward form of the characters. More importantly, the 
strokes of Chinese characters have no practical meaning. They exist in isolation. It is even more difficult for beginners to remember the stroke order of Chinese characters in a particular order. Related research shows that if some parts of the learning materials can be visualised, it is highly recommended to use the visualisation strategies to assist learning(Leahy \& Sweller, 2005). In this study, we associate each stroke, visualise each stroke as a familiar object in daily life, make these strokes meaningful, make it easier for students to understand and remember, thereby reducing the intrinsic cognitive load(Clark et al., 2011).

In addition, people always construct new knowledge based on existing knowledge (Sang, 2004), and learners' original knowledge level will affect their understanding of the new learning content. For the same learning material, if the elements in the learning material are highly interactive, then for learners with a higher level of knowledge, the intrinsic cognitive load produced will be lower than that of learners with a lower level of knowledge. In this research, since the learners have zero foundation and have never learned Chinese before, the influence of the learners on the intrinsic cognitive load is not under our consideration

\section{Strategies and Application of Increasing Germane Cognitive Load}

Germane cognitive load can promote learning. It is caused by cognitive activities directly related to learning(Paas \& Van Gog, 2006). During the learning process, learners devote unused cognitive resources to higher-level cognitive activities directly related to the current learning content, such as reasoning, induction, analogy, etc., and then there will be a germane Cognitive load.

The strategies to increase the germane cognitive load are closely related to the learners themselves. Methods to improve learning motivation are usually adopted. Learning motivation is an essential factor affecting the success of learning. When faced with relatively abstract or incomprehensible learning materials(Paas et al., 2005), learners with high learning motivation will actively deep-process the learning materials through different methods such as association, generalization, and deduction, thereby improving learning efficiency. At this time, germane cognitive load increases, but the process of increasing the germane cognitive load places higher requirements on learners. Each learner's abilities and levels are different. Not everyone can associate, generalize, and deduct. When designing the stroke order motion graphics of Chinese characters, the teaching targets are Chinese language beginners. They have never learned Chinese characters before, and some not never even seen a Chinese character before. It will be more difficult for them to actively engage in thinking activities such as association and generalization in the learning process. In this case, their learning motivation is relatively weak, so we can adopt the passive processing mode to guide learners to construct schemas to increase the effective cognitive load.

In this research, the authors use storytelling to increase learners' cognitive load and require learners to understand how to establish connections between stroke orders when watching animated stories so that strokes no longer exist in isolation. At the same time, they can also remember the stroke order of Chinese characters through animated stories. Compelling storytelling can mobilize students' learning motivation, increase learning interest, create a proactive learning atmosphere, and ultimately turn passive acceptance into active acceptance.

\section{Strategies and Application of Reducing Extraneous Cognitive Load}

Extraneous cognitive load is caused by instructional design, specifically manifested in the improper organization and presentation of learning materials(Paas et al., 2003). Inappropriate instructional design will distract learners, allocate too many cognitive resources to learning activities unrelated to the target learning content, and increase learners' extraneous cognitive load. This cognitive load will cause trouble to learners, reduce learning effect and learning efficiency. Therefore, the extraneous cognitive load can be reduced by optimizing the organization and presentation of learning materials to promote learning. The strategy of deleting redundant information and avoiding distraction can optimize the organization and presentation of learning materials. 


\section{Deleting Redundant Information}

In instructional design, redundancy occurs when the same information is presented in different ways or unnecessary additional information is presented (Sweller, 2005). The redundancy effect is a state of learning caused by improper teaching design. It will cause learners to produce additional cognitive processes and cause cognitive burdens. This cognitive burden will interfere with the content that needs to be learned. The redundant information here refers to the presentation of information related to the learning content but is repetitive or the presentation of unneeded information not associated with the learning content. Research shows that removing redundant information may promote learners' learning ability (Chandler \& Sweller, 1991).

For example, when describing a tree branch, using graphics to represent the branch and add the text to the branch picture will cause redundant information on the screen. To avoid the impact of redundant information on the learner's extraneous cognitive load, in coordinating the overall picture, you should consider choosing one of them. Either a branch of the text. In some cases, graphics are more vivid than text and are easier for learners to recognize. If graphic images can express the content intuitively and clearly, adding the text in the explanation is unnecessary.

In traditional instructional design, some decorative patterns or special symbols are added to enhance an image's visual effect. These patterns or symbols can indeed play a role in beautifying the image. However, it also drives learners to pay more attention to such patterns and symbols, caused distraction. The cognitive resources that need to be devoted to learning are reduced and further reduces the learning effect. In instructional design, this should be avoided as much as possible. There are two background images shown in figure 1, one with a pattern and the other with a solid colour. If presented separately, most people will think that the background image with the pattern is nice visually, but this will let the learner generate additional cognitive processing and occupy the cognitive resources more. Therefore, the authors use a solid-colour background image to create the Chinese characters' stroke order motion graphics.

\section{Figure 1: Design}

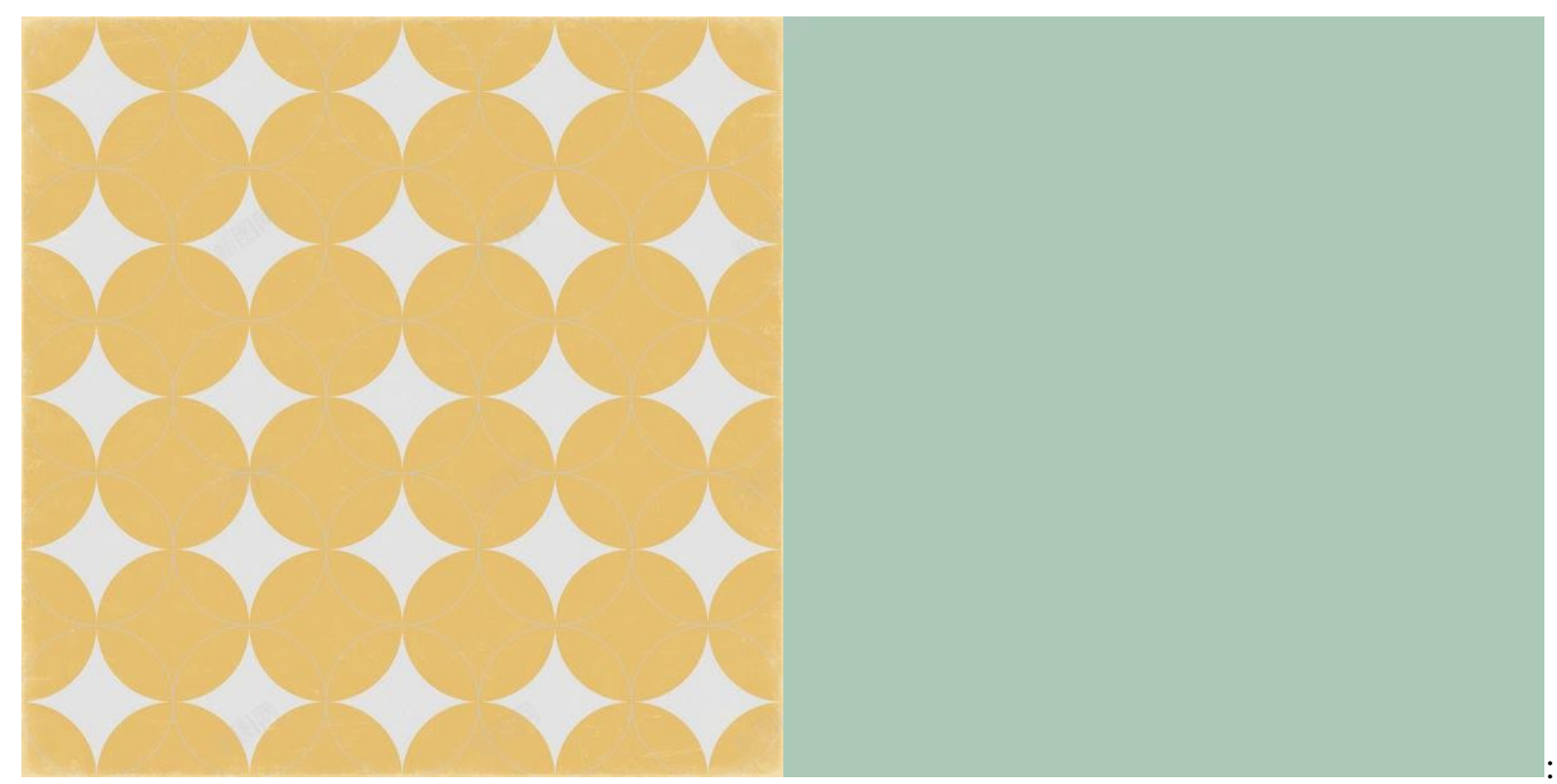

\section{Avoid Split-Attention}

Relevant teaching materials are divided into different parts and presented in chronological or spatial order, which will produce a split-attention effect(Chandler \& Sweller, 1992). Learners who use this teaching materials need to identify these teaching materials separately. They need to consume cognitive resources and construct their connections to understand the content conveyed by the learning materials. 
This process will produce a high extraneous cognitive load. To avoid distraction, the authors use animation and narration simultaneously when designing the Chinese characters' stroke order motion graphics and kept synchronized presentation.

In the process of separating the Chinese character stroke, the separated strokes need to be presented from the native characters one by one. At this time, it should be noted that the original characters and the separated strokes need to be typeset into one screen and presented next to each other. It will be hard for beginners to understand if the original character and the separated strokes are not in the same picture or far apart. It is difficult for them to see which part of the stroke corresponds to the original character. They need to waste some cognitive resources to search for information and then integrate the relevant information.

\section{The Teaching Process Involves the Chinese Characters Stroke Order Motion Graphics}

Herbart's four-stage teaching method is used as a guide for designing the presentation module of stroke order motion graphics of Chinese characters. Herbart believes that when students accept new things, they must go through the four stages of clarity, association, system, and method. Since the method stage is mainly realized by practice, the original intention of the Chinese characters' stroke order motion graphic design is to be used as an auxiliary teaching tool. This stage can be completed orally by teachers in class. Therefore, this stage does not appear in the design of stroke order motion graphics of Chinese characters. Table 2 describes the teaching objectives, methods, and corresponding motion graphic modules of the three stages in this research.

Table 2: teaching objectives, methods, and corresponding motion graphic modules

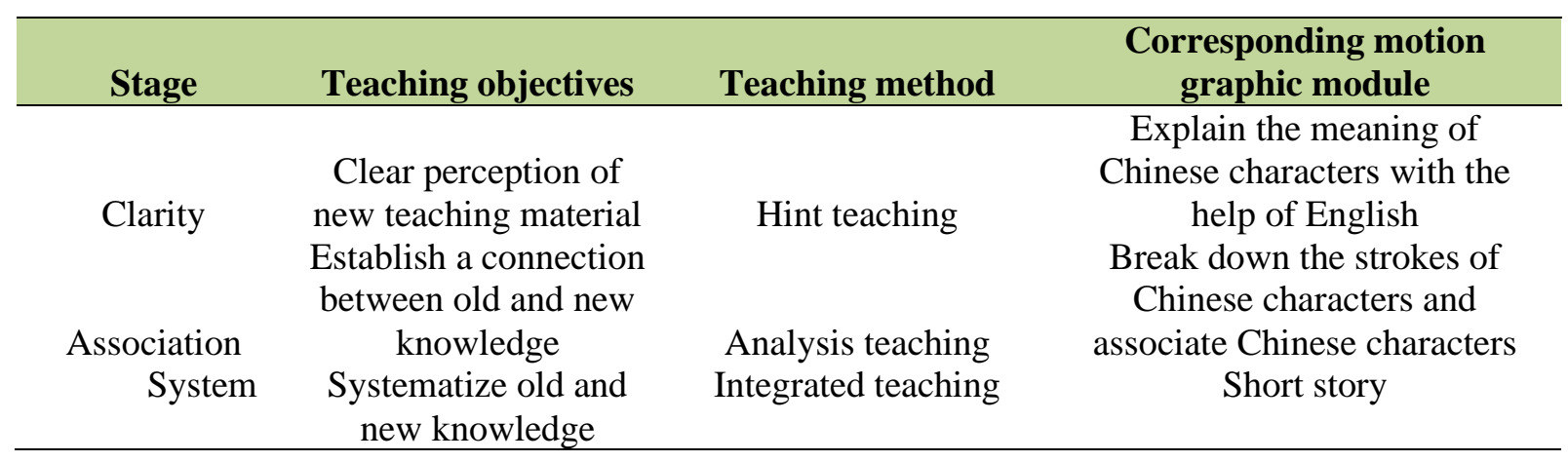

\section{Development}

Motion graphic is the product of designer's creativity, and the current academic circles have not clearly defined its specific development process. We can develop the animation production process in three stages: preproduction, production, and postproduction (Gossman, 2011). Each production stage contains multiple steps, which is a complicated process. However, in the specific development process, the production steps of each motion graphic are different, which depends on the background of the motion graphic development, involving factors such as the level of the designer, production time, budget, and customer needs(Krasner, 2013). In the preproduction work, the script focuses on text presentation, while the storyboard displays the text in the script through pictures. The most significant difference between motion graphics and traditional frame-by-frame animation is that it focuses on conveying information through the movement of text and graphics. As long as there is a script, experienced motion graphic designers can start graphic and motion design without storyboards. The first author has been engaged in motion graphic design for more than six years. In the actual production process, the process of storyboarding is omitted. The author combined this research's design requirements and determined the specific steps of Chinese characters' stroke order motion graphics design: script, voiceover, graphic design, animation, sound effects, background music and synthesis.

Script: The script is the written expression of the Chinese characters' stroke order motion graphic. It is used to convey product information and is the basis for subsequent development work. The quality of 
the script is directly related to the quality of the final motion graphic. The script of Chinese characters' stroke order motion graphics was carefully compiled based on the cognitive load theory. It was finally established after review by two Chinese teachers at the University of Science Malaysia.

Voiceover: Voiceover can be regarded as the audio performance of the script, which is the narration for the final motion graphic. The expressiveness of the voice is crucial to a motion graphic video, and it is directly related to the viewing experience of the target audience. In some cases, no matter how good the animation is, if it is accompanied by inappropriate sound, it will affect the quality of the entire video. To ensure the quality of the video, it is usually necessary to seek the help of voice actors. After considering the age, pronunciation, gender, and other factors that affect the voice style of the voice actors, we selected male voice actors who are a little older than the target audience for dubbing. The voice actors have a clear pronunciation, a gentle tone, and a strong sense of rhythm. After the dubbing is completed, the authors use Adobe Audition to denoise and subtract the duplication and pauses.

Graphic Design: Graphic design includes element design, text design, character design, and scene design. At this stage, the text in the script becomes an image through graphics. The process of visualization requires a creative design to reflect. Adobe Photoshop was used for graphic design. The principle of graphic design is to approach the common objects in life as much as possible in the simplest way.

Animation: Animation is a comprehensive process. It provides graphic action and combines it with dubbing. At this stage, Adobe Animate was used to complete the animation design, the text in the script is vividly displayed in front of the audience, and the sound and picture are synchronized.

Sound effects: The role of sound effects is to modification or highlight certain key objects. We downloaded some free high-quality sound effects through the Internet to match the key objects of the animation.

Background music: The role of background music is to set off the atmosphere of the motion graphic. It makes the motion graphic more vitality. Good background music can relax the students and make them better involved in learning. At this stage, it should be noted that the volume of the background music cannot exceed the voiceover. We downloaded a cheerful loyalty free background music through the Internet to integrate with the overall atmosphere of the motion graphic.

Synthesis: We integrate sound effects, background music, and animation through Adobe Premiere. Finally, the MOV format video is output, and then the file format is converted through the format factory software to obtain the MP4 format motion graphic.

\section{Implementation}

Beginners with zero foundation are unfamiliar with the design of Chinese characters and motion graphics. It is impractical for the target audience to be assessed at this stage. However, the researchers cannot predict whether there is a problem with the design. Therefore, we only used expert evaluation at this stage. For expert evaluation, the common practice is to use questionnaire surveys. However, questionnaire surveys have limitations and cannot discover the problems of the Chinese characters' stroke order motion graphics. Animation experts are usually unable to gather together at a particular time due to busy work schedules. After many considerations, the authors adopt the method of having five experts review Chinese characters' stroke order motion graphics and then directly give the review opinions. The first author has been in the animation field for nearly ten years. Designers widely use this method in the actual production process. According to the teaching strategy of the previous stage, the author first designed a prototype and delivered it to animation experts for review. Experts said that the stroke order motion graphics of Chinese characters are closely integrated with cognitive load theory. Herbart's four-stage teaching method is used appropriately, and the overall creativity is very good. However, there are some problems highlighted by them as well. Table 3 shows the opinions of experts summarized and summarized by the researchers. 
Table 3: The opinions of experts

\begin{tabular}{|c|c|}
\hline Problems to be improved & The purpose of the question \\
\hline Add opening animation & Clear learning goals \\
\hline Add Chinese character meaning the module & Explain the learning objectives \\
\hline $\begin{array}{l}\text { Add the name of the split object in the Chinese } \\
\text { character split part }\end{array}$ & $\begin{array}{l}\text { Make it easier for students to understand the } \\
\text { decomposition process }\end{array}$ \\
\hline $\begin{array}{l}\text { Add narration to the Chinese character split } \\
\text { part }\end{array}$ & $\begin{array}{l}\text { Make it easier for students to understand the } \\
\text { decomposition process }\end{array}$ \\
\hline Highlight learning difficulties & Deepen the impression of learning difficulties \\
\hline Slow down the speed of narration & Consider the acceptance of beginners \\
\hline Slow down the module interval time & Consider the acceptance of beginners \\
\hline Add subtitles & Consider students with poor English listening skil \\
\hline Unified design style & $\begin{array}{l}\text { Reduce the appearance of unfamiliar } \\
\text { things and prepare for mass production }\end{array}$ \\
\hline
\end{tabular}

The researcher has made modifications and improvements based on the above comments. Following are the links to the six completed Chinese characters' stroke order motion graphics prototype:

Sheng(生): https://www.youtube.com/watch?v=ZAMB0E1ViRI

Yang(羊): https://www.youtube.com/watch?v=GegFmLJWsto

Lai(来): https://www.youtube.com/watch?v=hLAe3rFVg1E

Shi(事): https://www.youtube.com/watch?v=tAiLMHGyNbI

Zhong(重): https://www.youtube.com/watch?v=pnmlJlwJmpg

Xiang(象): https://www.youtube.com/watch?v=gTKOn0quEH4\&t=4s

\section{Discussion}

Traditionally, the most significant difference between motion graphics and traditional animation is that the primary function of motion graphics is to convey information, while animation tells stories through characters. Through the development of Chinese characters' stroke order, this research aims to demonstrate that information conveying and storytelling can coexist in motion graphics. Storytelling is not a unique attribute of traditional animation. This research further proves the inclusiveness of motion graphics.

The purpose of the ADDIE model is to provide an instructional design method for curriculum designers. It provides basic steps for the development of Chinese characters' stroke order motion graphics. ADDIE model has been proved to be very effective for instructional design, although some scholars believe that the ADDIE model has many disadvantages, such as linear approach, timeconsuming, impractical comprehensive analysis in the early stage, etc. However, the ADDIE model is appropriate in this research because it is not dogmatic and invariable. The researchers can change the content of each stage or even each step according to their actual project situation. Therefore, there are many variants of the ADDIE model in the academic community.

The intrinsic cognitive load and germane cognitive load of cognitive load theory provide creativity for the content development of Chinese characters' stroke order motion graphics. However, we must also consider some of its teaching effects, such as split attention effect, redundancy effects, etc., which provide a guide for the interface design of Chinese characters' stroke order motion graphics. 


\section{Conclusion}

This paper describes the development process of Chinese characters' stroke order motion graphics and the affirmation of animation experts on Chinese characters' stroke order motion graphics. The difficulty of remembering the stroke order of Chinese characters is a global problem in teaching Chinese as a second language, and it can be solved by using the motion graphic approach, as demonstrated in this research. This research also formulated a series of development steps based on related theories guiding motion graphic designers. A preproduction prototype is a necessary production step, regardless of whether the designer is experienced or inexperienced. It was supported in the expert evaluation carried out. Further studies are needed to explore and measure the effectiveness of the Chinese characters' stroke order to the target audiences.

\section{References}

Chandler, P., \& Sweller, J. (1991). Cognitive load theory and the format of instruction. Cognition and Instruction, 8(4), 293-332.

Chandler, P., \& Sweller, J. (1992). The split-attention effect as a factor in the design of instruction. British Journal of Educational Psychology, 62(2), 233-246.

Clark, R. C., Nguyen, F., \& Sweller, J. (2011). Efficiency in learning: Evidence-based guidelines to manage cognitive load. John Wiley \& Sons.

Ding, S., \& Saunders, R. A. (2006). Talking up China: An analysis of China's rising cultural power and global promotion of the Chinese language. East Asia, 23(2), 3-33.

Fatimah, A. S., \& Santiana, S. (2017). Teaching in 21st century: Students-teachers' perceptions of technology use in the classroom. Script Journal: Journal of Linguistic and English Teaching, 2(2), 125.

Gossman, R. (2011). The Animation Production Process. Recuperado de http://nir3d. com/handouts/Handouts\% 20History\% 20of\% 20Animation.

Hasler, B. S., Kersten, B., \& Sweller, J. (2007). Learner control, cognitive load and instructional animation. Applied Cognitive Psychology: The Official Journal of the Society for Applied Research in Memory and Cognition, 21(6), 713-729.

Hsiung, H.-Y., Chang, Y.-L., Chen, H.-C., \& Sung, Y.-T. (2017). Effect of stroke-order learning and handwriting exercises on recognizing and writing Chinese characters by Chinese as a foreign language learners. Computers in Human Behavior, 74, 303-310.

Krasner, J. (2013). Motion graphic design: applied history and aesthetics. Taylor \& Francis.

Leahy, W., \& Sweller, J. (2005). Interactions among the imagination, expertise reversal, and element interactivity effects. Journal of Experimental Psychology: Applied, 11(4), 266.

Leppink, J., \& van den Heuvel, A. (2015). The evolution of cognitive load theory and its application to medical education. Perspectives on Medical Education, 4(3), 119-127.

Li, Z. (2003). Chinese character stroke order dictionary software. Computer Applications and Software, 20(5), 79-80.

Marcus, N., Cleary, B., Wong, A., \& Ayres, P. (2013). Should hand actions be observed when learning hand motor skills from instructional animations? Computers in Human Behavior, 29(6), 21722178. https://doi.org/https://doi.org/10.1016/j.chb.2013.04.035

Mason, L., Lowe, R., \& Tornatora, M. C. (2013). Self-generated drawings for supporting comprehension of a complex animation. Contemporary Educational Psychology, 38(3), 211224.

Miller, G. A. (1956). The magical number seven, plus or minus two: Some limits on our capacity for processing information. Psychological review, 63(2), 81.

Paas, F., Renkl, A., \& Sweller, J. (2003). Cognitive load theory and instructional design: Recent developments. Educational psychologist, 38(1), 1-4.

Paas, F., Tuovinen, J. E., Van Merrienboer, J. J., \& Darabi, A. A. (2005). A motivational perspective on the relation between mental effort and performance: Optimizing learner involvement in instruction. Educational technology research and development, 53(3), 25-34.

Paas, F., \& Van Gog, T. (2006). Optimising worked example instruction: Different ways to increase germane cognitive load. In: Elsevier. 
Packard, J. L. (1990). Effects of time lag in the introduction of characters into the Chinese language curriculum. The Modern Language Journal, 74(2), 167-175.

Richey, R. C., \& Klein, J. D. (2014). Design and development research. In Handbook of research on educational communications and technology. Springer.

Richey, R. C., \& Klein, J. D. (2014). Design and development research: Methods, strategies, and issues. Routledge.

Sang, X. (2004). Learning science and technology. Cultivation of College Students' learning ability in the information age. . Higher Education Press, 227.

Sweller, J. (1988). Cognitive load during problem solving: Effects on learning. Cognitive science, 12(2), 257-285.

Sweller, J. (1994). Cognitive load theory, learning difficulty, and instructional design. Learning and Instruction, 4(4), 295-312.

Sweller, J. (2005). The redundancy principle in multimedia learning. The Cambridge handbook of multimedia learning, 159-167.

Sweller, J. (2010). Element interactivity and intrinsic, extraneous, and germane cognitive load. Educational psychology review, 22(2), 123-138.

Taft, M., \& Chung, K. (1999). Using radicals in teaching Chinese characters to second language learners. Psychologia, 42(4), 243-251.

Tan, L. H., Spinks, J. A., Eden, G. F., Perfetti, C. A., \& Siok, W. T. (2005). Reading depends on writing, in Chinese. Proceedings of the National Academy of Sciences, 102(24), 8781-8785.

Wong, A., Leahy, W., Marcus, N., \& Sweller, J. (2012). Cognitive load theory, the transient information effect and e-learning. Learning and Instruction, 22(6), 449-457. https://doi.org/https://doi.org/10.1016/j.learninstruc.2012.05.004

Zhen, Z. (2015). Advantages and thinking on design of Chinese characters' graphics. Studies in Literature and Language, 11(2), 82-87.

Zhu, Y., \& Wang, L. (2013). Flash-based Chinese character stroke order courseware production method. China Education Information Technology, 24. 